\title{
Accelerometer- versus questionnaire-based assessment of physical activity and their changes over time in patients with COPD
}

This article was published in the following Dove Press journal:

International Journal of COPD

10 April 2017

Number of times this article has been viewed

\author{
Noriane A Sievi' \\ Thomas Brack ${ }^{2}$ \\ Martin H Brutsche ${ }^{3}$ \\ Martin Frey ${ }^{4}$ \\ Sarosh Irani ${ }^{5}$ \\ Jörg D Leuppi ${ }^{6}$ \\ Robert Thurnheer ${ }^{7}$ \\ Malcolm Kohler ${ }^{1,8}$ \\ Christian F Clarenbach'
}

'Pulmonary Division, University Hospital of Zurich, Zurich, ${ }^{2}$ Pulmonary

Division, Cantonal Hospital of

Glarus, Glarus, ${ }^{3}$ Pulmonary Division,

Cantonal Hospital of St Gallen,

St Gallen, ${ }^{4}$ Pulmonary Division,

Clinic Barmelweid, ${ }^{5}$ Pulmonary

Division, Cantonal Hospital of Aarau, Aarau, ${ }^{6}$ University Clinic of Internal Medicine, Cantonal Hospital Baselland, ${ }^{7}$ Pulmonary Division, Cantonal Hospital of Münsterlingen, Münsterlingen, ${ }^{8}$ Zurich Centre for Integrative Human Physiology, University of Zurich, Zurich, Switzerland
Correspondence: Christian F Clarenbach Pulmonary Division, University Hospital of Zurich, Raemistrasse 100, 809| Zurich, Switzerland Email christian.clarenbach@usz.ch
Background and objective: Physical activity (PA) is an important outcome parameter in patients with COPD regarding hospitalizations and mortality. Both objective assessment by accelerometers and self-evaluation by questionnaires were used in studies investigating PA in COPD. Whether self-reported questionnaires can adequately reflect PA and its changes over time compared to objective assessments has not been thoroughly investigated in COPD. In this COPD cohort study, we evaluated whether PA measured by accelerometer and its annual changes can also be assessed by self-reported questionnaires.

Methods: In 178 COPD patients with at least two assessments of PA, the agreement between objectively measured and self-reported activity was analyzed by Bland-Altman plots. Daily PA was assessed by a triaxial activity monitor over 1 week and by the self-reported German PA questionnaire 50+.

Results: Comparison between the two methods of measurement revealed no convincing agreement with a mean difference and limits of agreement ( \pm 1.96 standard deviation $[\mathrm{SD}])$ of time spent in at least moderate PA ( $>3$ metabolic equivalent of task [MET]) of -77.6 $(-340.3 / 185.2) \mathrm{min} /$ day, indicating a self-reported overestimation of PA by the questionnaire. The mean difference and limits of agreement $( \pm 1.96 \mathrm{SD})$ in the annual change of PA was $1.2 \mathrm{~min} /$ day (-208.2/282.6 $\mathrm{min} /$ day), showing also a poor agreement on an individual level.

Conclusion: Evaluation of objectively measured and self-reported PA and their annual changes revealed no agreement in patients with COPD. Therefore, the evaluated questionnaire seems not helpful for measurement of PA and its changes over time.

Keywords: activity monitor, activity questionnaire, airflow limitation, COPD

\section{Introduction}

An inactive lifestyle is a prominent feature in patients with COPD and has been linked to an increased risk of hospitalizations and mortality. ${ }^{1}$ Due to this close relationship between the level of physical activity (PA) and general health, assessment of PA in daily life has recently emerged as an important outcome measure in COPD. To provide reliable information, an accurate assessment of the amount and intensity of PA is required. Accelerometers have been evaluated against the gold standard indirect calorimetry and doubly labeled water in patients with COPD. ${ }^{2,3}$ Among these studies, the triaxial accelerometer SenseWear ${ }^{\circledR}$ was valid and responsive in this patient group. Questionnaire-based assessments of PA are frequently used in research settings due to their simplicity, high patient acceptance and low costs. However, whether they reflect the actual level of PA and its changes is still unclear..$^{47}$ Outside research settings, activity monitors are rarely used in general practice. Despite the mentioned concerns submit your manuscript Dovepress If in 10
International Journal of COPD 2017:12 11113-1118

(c) (1) (5) 2017 Sievi et al. This work is published and licensed by Dove Medical Press Limited. The full terms of this license are available at https://www.dovepress.com/terms.php cc) and incorporate the Creative Commons Attribution - Non Commercial (unported, v3.0) License (http://creativecommons.org/licenses/by-nd/3.0/). By accessing the work you hereby accept the Terms. Non-commercial uses of the work are permitted without any further permission from Dove Medical Press Limited, provided the work is properly attributed. For permission for commercial use of this work, please see paragraphs 4.2 and 5 of our Terms (https://www.dovepress.com/terms.php). 
about questionnaires not providing the exact level of PA, it would be attractive to have a validated questionnaire that allows to capture PA in a cross-sectional and longitudinal setting in an easy manner in COPD patients. The German physical activity questionnaire 50+ (G-PAQ-50+) was developed for an elderly ( $>50$ years) German population and estimates the duration of patients' activity of the previous week. The G-PAQ-50+ questionnaire includes questions on the amount (min/week) and type of housework, gardening, leisure time, sport and profession. ${ }^{8}$

In this study, we compared objectively assessed PA and its annual changes to PA estimations by a questionnaire in a COPD population.

\section{Methods}

\section{Subjects}

This study is a sub-analysis of data retrieved from The Obstructive Pulmonary Disease Outcomes Cohort of Switzerland (TOPDOCS). TOPDOCS is a prospective, longitudinal cohort study including COPD patients and annual assessments in seven study centers in Switzerland. Patients were recruited during ambulatory visits in the pulmonary clinics or during hospital stay. Patients aged between 40 and 75 years with confirmed COPD according to the Global Initiative for Chronic Obstructive Lung Disease (GOLD) guidelines ${ }^{9}$ were assessed for eligibility between October 2010 and December 2016. Patients were excluded if they suffered from mental or physical disability precluding informed consent or compliance with the protocol. If they had suffered from a COPD exacerbation within the last 6 weeks, the study visits were postponed until symptoms resolved to a steady state. Since the assessment of changes in PA was a principal outcome, only patients with at least two study visits were included in this analysis.

The study was conducted in accordance with the Declaration of Helsinki of the World Medical Association. The Ethics Committee of the Canton of Zurich approved the study (EK-ZH-NR: 2011-0106), and the study was registered at www.ClinicalTrials.gov, NCT01527773. All subjects gave written informed consent to participate.

\section{Measurements}

To compare objectively measured and self-reported questionnaire-assessed PA, patients were equipped with an activity monitor over 1 week and were asked to fill in a questionnaire rating their activity over this period. Time spent at least at moderate activity was investigated as outcome and available from both instruments. Moderate activity was defined by a metabolic equivalent of task $(\mathrm{MET})>3$; one MET is equal to the energy expenditure during rest $(3.5 \mathrm{~mL}$ $\left.\mathrm{O}_{2} \cdot \mathrm{kg}^{-1} \min ^{-1}\right)$.

\section{Activity monitor (SenseWear Pro ${ }^{\mathrm{TM}}$ )}

Objectively assessed PA was measured by a triaxial accelerometer of a multisensory activity monitor (SenseWear Pro; Bodymedia Inc., Pittsburgh, PA, USA) that has been validated in COPD patients. ${ }^{2}$ The monitor was worn on the upper left arm over the triceps muscle for 7 consecutive days once a year. The minimal threshold for valid data was set at 4 days with a minimum of $22.5 \mathrm{~h} /$ day. ${ }^{10}$ The data output of the SenseWear device allowed quantification of daily activity time (minutes) $>3 \mathrm{MET}$.

\section{G-PAQ-50+ questionnaire}

This self-reported questionnaire was used to estimate the duration of patients' activity of the previous week. The questionnaire was filled in after wearing the SenseWear. The G-PAQ-50+ questionnaire includes questions on the amount (min/week) and type of the main activities in elderly people including housework, gardening, leisure time, sport and profession. ${ }^{8}$ The different activities are assigned to intensity codes represented by MET from the compendium of PAs. ${ }^{11}$ For analysis, all activities above a MET $>3$ were summarized, and the daily mean was calculated (minutes of activity $>3$ MET per day). The questionnaire has been validated in an elderly population and derives from a German-speaking country.

\section{Lung function}

All patients underwent standard pulmonary functional testing according to the American Thoracic Society guidelines ${ }^{12}$ to measure forced expiratory volume in 1 second $\left(\mathrm{FEV}_{1}\right)$, forced vital capacity (FVC), residual volume expressed as percent of total lung capacity (RV/TLC) and diffusing capacity of the lung for carbon monoxide (DLCO). Only values after bronchodilation are reported.

\section{Data analysis and statistics}

All results are shown as mean values (standard deviation [SD]) or median (quartiles) unless otherwise stated. BlandAltman plots were used to investigate the agreement between the two methods of measurement by computing the mean difference and limits of agreement $( \pm 1.96 \mathrm{SD})$. The difference was calculated as objectively measured (SenseWear) - self reported (G-PAQ-50+) time spent at MET >3. Furthermore, intraclass correlation coefficient (ICC) was calculated. Stratification by GOLD was investigated by separating 
$\mathrm{mild} /$ moderate from severe/very severe COPD $\left(\mathrm{FEV}_{1} \leq 50 \%\right.$ predicted). To assess the measurements agreement in different classes of PA, patients were categorized into quartiles of time spent at moderate activity measured by accelerometer. Statistical analysis was performed with STATA 14 (StataCorp, College Station, TX, USA).

\section{Results}

\section{Study participants}

A total of 178 COPD patients (59 females) were analyzed (Figure 1) and had at least two assessments of PA. Three study visits were performed by 103 patients; four or more visits by 38 patients. In total, 513 assessments of selfreported and objective PA were investigated. Of the COPD patients included, $46 \%$ had a spirometric GOLD stage $1 / 2$, $37 \%$ stage 3 and $17 \%$ stage 4 . The median (quartiles) age of this cohort was 64 (60-69) years, body mass index (BMI)

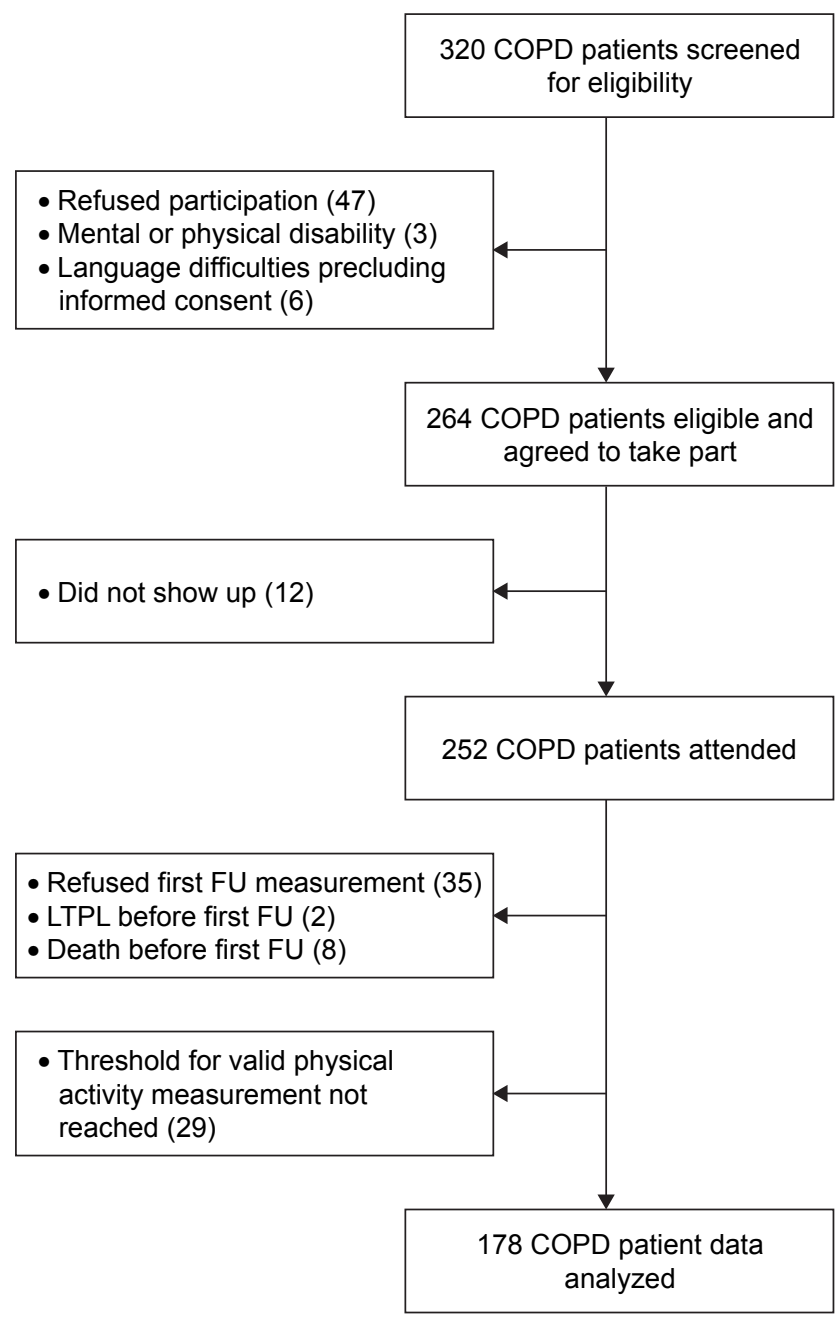

Figure I Study flow.

Abbreviations: FU, follow-up; LTPL, lung transplantation. was $26(23-28) \mathrm{kg} / \mathrm{m}^{2}$ and $23 \%$ of the COPD patients were current smokers. The detailed patient characteristics are shown in Table 1.

\section{Agreement between the two methods of measurement}

Activity time spent $>3$ MET

Mean $( \pm \mathrm{SD})$ time spent at moderate PA $(>3 \mathrm{MET})$ measured by the accelerometer was $65( \pm 89.4) \mathrm{min} /$ day compared to $146( \pm 143.1) \mathrm{min} /$ day measured by the questionnaire.

Direct comparison between the two methods of measurement revealed no convincing agreement. The mean difference and limits of agreement $( \pm 1.96 \mathrm{SD})$ of time spent in at least moderate PA (>3MET) was -77.6 ( -340.3 to 185.2$) \mathrm{min} /$ day indicating an overestimation of PA by the questionnaire (Figure 2). The two measurements showed a poor to fair ICC of 0.40 . This overestimation of PA was not specific for gender (mean difference and limits of agreement in male -79.6 [ -358.4 to 199.2$]$ and -73.8 [ -304.5 to 156.8$]$ in female). Stratification by GOLD stages showed that neither in severe/very severe (mean difference and limits of agreement -61.7 [-259.7 to 136.4$]$ ) nor in mild/moderate COPD (mean difference and limits of agreement -97.2 [-418.3 to 224.0]) a better agreement between the two methods could be detected. Separating active from very inactive patients also revealed no good agreement between the two methods.

\section{Annual change of activity time $>3$ MET}

When comparing the annual change in moderate activity, no agreement between the two methods of measurement was found with an ICC of 0.00. Although the mean difference (1.2 $\mathrm{min} /$ day) between objective and self-reported PA was comparable, the wide range of the limits of agreement

Table I Patients' characteristics at baseline $(\mathrm{N}=178)$

\begin{tabular}{ll}
\hline Patients' characteristics & \\
\hline Age, years & $64(60-69)$ \\
Male/female, n & $119 / 59$ \\
BMI, kg/m² & $25.6(22.5-28.4)$ \\
Current smoker, n (\%) & $4 \mathrm{I}(23)$ \\
Pack years of smoking, n & $40(30-60)$ \\
FEV,$\%$ pred & $46(33-64)$ \\
FVC, \% pred & $82(67-95)$ \\
RV/TLC, \% & $54( \pm 10.7)$ \\
DLCO, \% pred & $50(36-69)$ \\
Objectively measured activity >3MET, min/day & $39(16-82)$ \\
\hline
\end{tabular}

Note: Values are median (IQR) or mean ( $(\mathrm{SD})$, unless otherwise stated.

Abbreviations: BMI, body mass index; $\mathrm{FEV}_{1}$, forced expiration volume in I second; $\%$ pred, \% predicted; FVC, forced vital capacity; RV/TLC, residual volume to total lung capacity; DLCO, diffusing capacity of the lung for carbon monoxide; MET, metabolic equivalent of task; IQR, interquartile range; SD, standard deviation. 


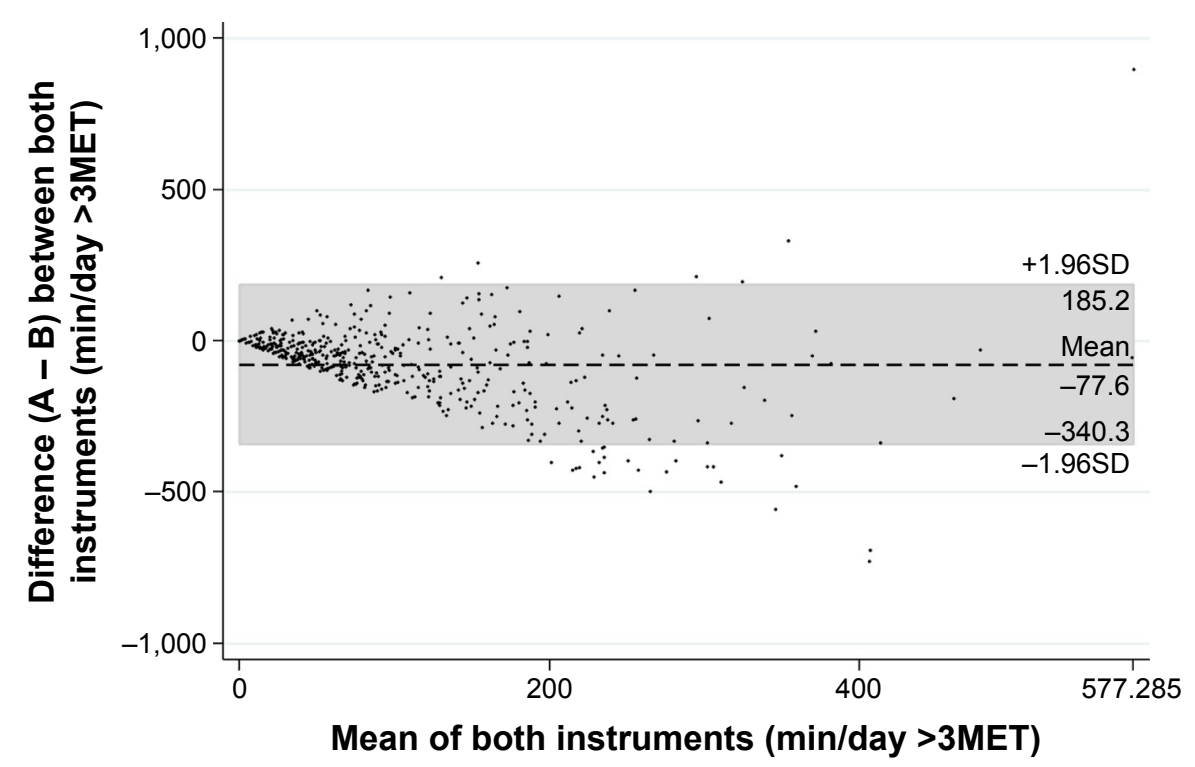

Figure 2 Bland-Altman plot of differences between objectively measured (A) and self-reported (B) physical activity against their mean. Note: The mean difference and limits of agreement $( \pm$ I.96SD) are represented by the dashed line and the gray marked area, respectively. Abbreviations: MET, metabolic equivalent of task; SD, standard deviation.

(-208.2 to $282.6 \mathrm{~min} /$ day) indicates that on an individual level there is also no agreement between the methods (Figure 3).

\section{Discussion}

This study investigated the agreement between objectively measured and self-reported PA and its changes over time in patients with COPD. The agreement between direct and selfreported PA was poor. A novel finding is that in a longitudinal prospective assessment, the objectively measured yearly changes in PA could not be reproduced by self-reported questionnaires. We found that COPD patients widely overestimated their time spent at moderate activity ( $>3 \mathrm{MET})$.

In recent years, assessment of daily PA gained importance as an outcome measure in COPD since a close association between a low level of PA and poor prognosis was demonstrated. ${ }^{13}$ While data from larger COPD cohorts

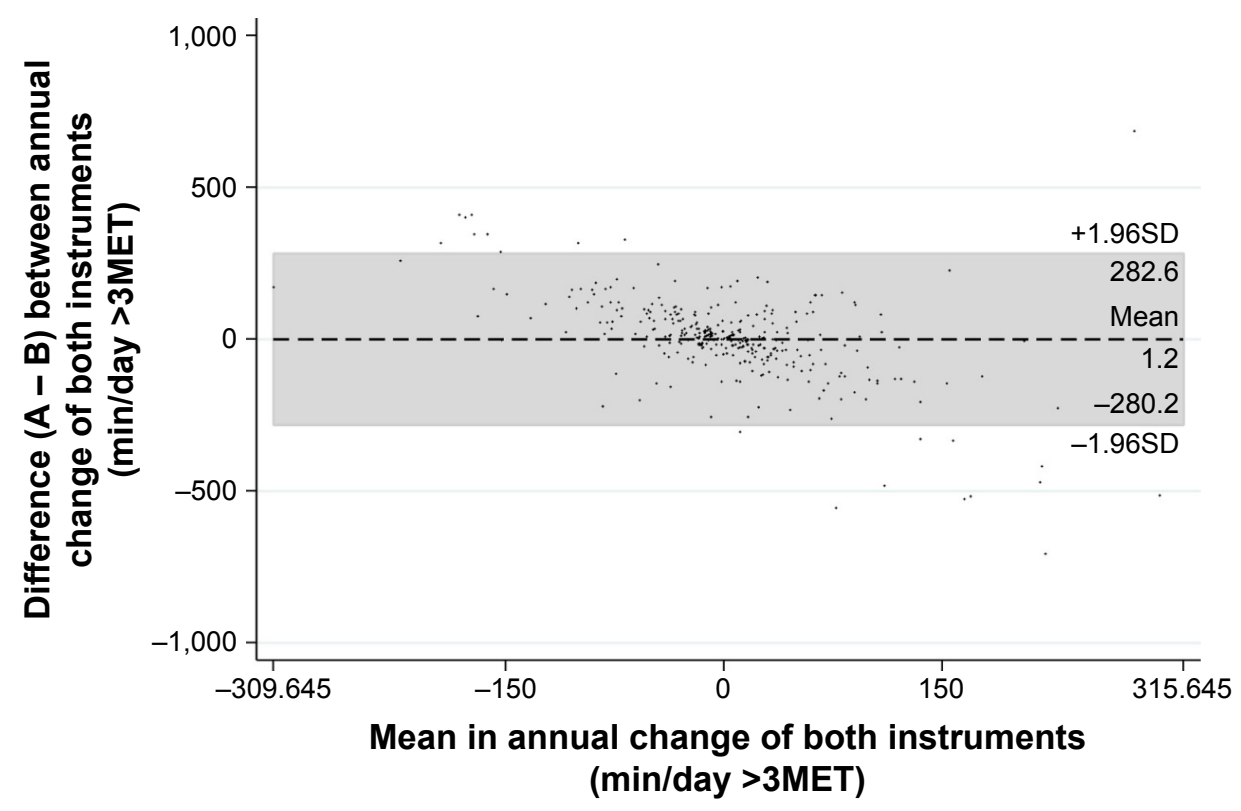

Figure 3 Bland-Altman plot of differences between the annual change of objectively measured (A) and self-reported (B) physical activity against their mean. Note: The mean difference and limits of agreement $( \pm$ I.96SD) are represented by the dashed line and the gray marked area, respectively. Abbreviations: MET, metabolic equivalent of task; SD, standard deviation. 
included assessment of PA mostly by questionnaires, ${ }^{1,14,15}$ present COPD studies with activity as an outcome parameter measured PA more frequently by accelerometers. ${ }^{16,17}$ Since assessment of activity by accelerometer is less practicable and more expensive than by self-reported questionnaires, it would be desirable to have a validated questionnaire that allows to capture PA in a cross-sectional and longitudinal setting in COPD patients. Previous studies in various settings investigated the comparison between direct and self-reported measures of PA since questionnaire-based assessments of PA are frequently used in research settings due to their simplicity, high patient acceptance and low costs. ${ }^{4,5,18}$ Garfield et $\mathrm{al}^{6}$ showed inconsistent results regarding the agreement between accelerometer and different activity questionnaires in 43 patients with COPD in a cross-sectional setting. Only the Stanford Seven-Day Physical Activity Recall questionnaire was able to identify active and very inactive patients. In another study, Donaire-Gonzalez et a ${ }^{19}$ validated the Yale Physical Activity Survey in 172 COPD patients who were equipped with an accelerometer for 8 days. A wide variability in agreement between the two methods was observed. Therefore, a validated and widely used PA questionnaire in patients with COPD is still missing.

In agreement with our findings, a systematic review by Prince et $\mathrm{al}^{20}$ on the comparison of direct versus selfreported measures for PA in adults showed also that self-reported PA by questionnaires were both over- and underestimated compared to objectively measured PA. Our results showed that COPD patients overestimate their mean daily time spent at moderate activity by a factor of 2.2 compared to the accelerometer, although the questionnaire with a recall period of 7 days covered the wearing time of the accelerometer. This finding was previously reported by Pitta et al. ${ }^{21}$ In their study, COPD patients significantly overestimated their walking time and underestimated their standing time. While evaluating the agreement between the objectively measured and self-reported PA allowed no interpretation on possible clusters of over- or underestimation based on patients' characteristics, the analysis of the agreement between the two methods on annual changes showed that COPD patients with an improvement in PA over time tend to overestimate their PA, while patients with an annual decrease in PA tend to underestimate their activity level in a comparable amount. The findings of our study implicate that self-reported PA is less valid to investigate the time spent at moderate activity and to assess their annual changes. Therefore, the choice of the measurement method may have a crucial influence on the detected PA and on observed study results. Therefore, questionnaires seem less sensitive to assess PA as an outcome measure in COPD.

Nevertheless, questionnaires capture data that cannot be measured by an accelerometer such as patients' experience of symptoms while being active. Thus, a combination of a questionnaire- and accelerometer-based assessment such as recently introduced by Gimeno-Santos et $\mathrm{al}^{22}$ should be implemented in future trials on PA in COPD patients.

One limitation of this study is that the questionnaire used has not been widely used in COPD patients. However, it has been validated in an elderly population and derives from a German-speaking country; thus, there was no need for a validated translation in our Swiss cohort.

The current findings in our COPD cohort suggest that there is no reliable agreement between the time spent at moderate PA measured by a self-reported questionnaire and an accelerometer. Although questionnaires require a lower effort than objective measurements, it seems not promising to rely on them evaluating PA in COPD.

\section{Acknowledgments}

This study was supported by Lunge Zurich, Lung league of both Basel, Gottfried and Julia Bangerter-Rhyner foundation, Freiwillige Akademische Gesellschaft Basel, Lung league of Canton Thurgau, Lung league of Canton St Gallen, Lung league of Canton Aargau and Lung league of Canton Glarus.

\section{Author contributions}

All authors contributed toward data analysis, drafting and critically revising the paper, gave final approval of the version to be published, and agree to be accountable for all aspects of the work.

\section{Disclosure}

The authors report no conflicts of interest in this work.

\section{References}

1. Garcia-Aymerich J, Lange P, Benet M, Schnohr P, Anto JM. Regular physical activity reduces hospital admission and mortality in chronic obstructive pulmonary disease: a population based cohort study. Thorax. 2006;61(9):772-778.

2. Van Remoortel H, Raste Y, Louvaris Z, et al; PROactive consortium. Validity of six activity monitors in chronic obstructive pulmonary disease: a comparison with indirect calorimetry. PLoS One. 2012;7(6):e39198.

3. Rabinovich RA, Louvaris Z, Raste Y, et al; PROactive Consortium. Validity of physical activity monitors during daily life in patients with COPD. Eur Respir J. 2013;42(5):1205-1215.

4. van Gestel AJ, Clarenbach CF, Stowhas AC, et al. Predicting daily physical activity in patients with chronic obstructive pulmonary disease. PLoS One. 2012;7(11):e48081. 
5. Thyregod M, Bodtger U. Coherence between self-reported and objectively measured physical activity in patients with chronic obstructive lung disease: a systematic review. Int J Chron Obstruct Pulmon Dis. 2016;11: 2931-2938.

6. Garfield BE, Canavan JL, Smith CJ, et al. Stanford Seven-Day Physical Activity Recall questionnaire in COPD. Eur Respir J. 2012;40(2): 356-362.

7. DePew ZS, Garofoli AC, Novotny PJ, Benzo RP. Screening for severe physical inactivity in chronic obstructive pulmonary disease: the value of simple measures and the validation of two physical activity questionnaires. Chron Respir Dis. 2013;10(1):19-27.

8. Huy C, Schneider S. Instrument für die Erfassung der physischen Aktivität bei Personen im mittleren und höheren Erwachsenenalter Entwicklung, Prüfung und Anwendung des "German-PAQ-50+" [Instrument for the assessment of middle-aged and older adults' physical activity: design, eliability and application of the German-PAQ-50+]. Z Gerontol Geriatr. 2008;41(3):208-216. German.

9. Rabe KF, Hurd S, Anzueto A, et al. Global strategy for the diagnosis, management, and prevention of chronic obstructive pulmonary disease GOLD executive summary. Am J Respir Crit Care Med. 2007;176(6): 532-555.

10. Watz H, Pitta F, Rochester CL, et al. An official European Respiratory Society statement on physical activity in COPD. Eur Respir J. 2014; 44(6):1521-1537.

11. Ainsworth BE, Haskell WL, Herrmann SD, et al. 2011 Compendium of Physical Activities: a second update of codes and MET values. Med Sci Sports Exerc. 2011;43(8):1575-1581.

12. Miller MR, Hankinson J, Brusasco V, et al. Standardisation of spirometry. Eur Respir J. 2005;26(2):319-338.

13. Gimeno-Santos E, Frei A, Steurer-Stey C, et al; PROactive consortium. Determinants and outcomes of physical activity in patients with COPD: a systematic review. Thorax. 2014;69(8):731-739.
14. Esteban C, Quintana JM, Aburto M, et al. Impact of changes in physical activity on health-related quality of life among patients with COPD. Eur Respir J. 2010;36(2):292-300.

15. Yu T, Frei A, Ter Riet G, Puhan MA. Determinants of physical activity in patients with chronic obstructive pulmonary disease: a 5-year prospective follow-up study. Respiration. 2016;92(2):72-79.

16. Waschki B, Kirsten AM, Holz O, et al. Disease progression and changes in physical activity in patients with chronic obstructive pulmonary disease. Am J Respir Crit Care Med. 2015;192(3):295-306.

17. Sievi NA, Senn O, Brack T, et al. Impact of comorbidities on physical activity in COPD. Respirology. 2015;20(3):413-418.

18. Lichtman SW, Pisarska K, Berman ER, et al. Discrepancy between self-reported and actual caloric intake and exercise in obese subjects. N Engl J Med. 1992;327(27):1893-1898.

19. Donaire-Gonzalez D, Gimeno-Santos E, Serra I, et al. Validación del cuestionario de actividad física de Yale en pacientes con enfermedad pulmonar obstructiva crónica [Validation of the Yale Physical Activity Survey in chronic obstructive pulmonary disease patients]. Arch Bronconeumol. 2011;47(11):552-560. Spanish.

20. Prince SA, Adamo KB, Hamel ME, Hardt J, Connor Gorber S, Tremblay M. A comparison of direct versus self-report measures for assessing physical activity in adults: a systematic review. Int J Behav Nutr Phys Act. 2008;5:56.

21. Pitta F, Troosters T, Spruit MA, Decramer M, Gosselink R. Activity monitoring for assessment of physical activities in daily life in patients with chronic obstructive pulmonary disease. Arch Phys Med Rehabil. 2005;86(10):1979-1985.

22. Gimeno-Santos E, Raste Y, Demeyer H, et al; PROactive consortium. The PROactive instruments to measure physical activity in patients with chronic obstructive pulmonary disease. Eur Respir J. 2015;46(4): 988-1000.
International Journal of COPD

\section{Publish your work in this journal}

The International Journal of COPD is an international, peer-reviewed journal of therapeutics and pharmacology focusing on concise rapid reporting of clinical studies and reviews in COPD. Special focus is given to the pathophysiological processes underlying the disease, intervention programs, patient focused education, and self management protocols.

\section{Dovepress}

This journal is indexed on PubMed Central, MedLine and CAS. The manuscript management system is completely online and includes a very quick and fair peer-review system, which is all easy to use. Visit http://www.dovepress.com/testimonials.php to read real quotes from published authors. 